\title{
Sleep State Organization in Premature Infants of Less Than 35 Weeks' Gestational Age
}

\author{
L. CURZI-DASCAlovA, J. M. HGUEROA, M. EISELt, E. CHRISTOVA. A. VIRASSAMY.
} A. M. D'Al.LEST, H. GUIMARÂl:S. C. GAULTIER, AND M. DIIHAN

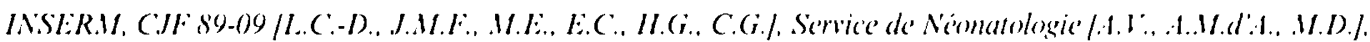

Hipital A. Béclire, 9214l Clamart, France

\begin{abstract}
To assess sleep organization in premature infants of $<35$ wk gestational age (w GA), we performed polygraphic recordings in 24 neurologically normal neonates (eight per group): artificially ventilated $27-30$ and 31-34 w GA infants and nonventilated 31-34 w GA infants. Sleep states were defined by concordance of EEG and rapid eye movement criteria. Uninterrupted active sleep periods of $>13 \mathrm{~min}$ and quiet sleep periods of $>5 \mathrm{~min}$ were observed in all babies, except in one 33 w GA rentilated infant. Intervals from the beginning of recording to the 1 st quiet sleep period varied from 0 to $63 \mathrm{~min}$ and intervals to the beginning of the longest sleep cycle varied from 5 to 84 min. Nonventilated 31-34 w GA infants had longer sleep cycles $(p<0.02)$, principally because of longer active sleep periods. However, percentages of different states in the cycles were similar in all groups. When body movements were required for state definition, amounts of active and quiet sleep diminished and the percentage of indeterminate sleep was augmented significantly. In conclusion, our study demonstrated that 1) sleep state differentiation is present as soon as $27 \mathrm{w} \mathrm{GA}$; and 2) artificial ventilation, performed in a highly specialized neonatal intensive care unit, does not modify sleep organization of neurologically normal premature infants. We hypothesize that this "earlier" sleep state differentiation, compared with previous data, may be related to improvements in neonatal intensive care over recent years. (Pediatr Res 34: 624-628, 1993)
\end{abstract}

Abbreviations
AS, active sleep
QS, quiet sleep
IS, indeterminate sleep
GA, gestational age
w GA, weeks' gestational age
REM, rapid eye movement

Sleep states are distinct situations, each having its specific characteristics and reflecting a particular mode of CNS function (1). The time of first appearance of AS and QS is controversial. In most cases, however, comparisons between studies are difficult because of variations in the parameters chosen for state definition. Recent data on differences in physiologic variables between epochs of AS and QS parameters are consistent with the view that state differentiation occurs earlier than suggested by some studies published before 1980. From 31-34 w GA, AS is distin-

Received January 14. 1993; accepted June 22. 1993

Correspondence: Dr. Lilia Curzi-Dascalova. INSERM. CJF 89-09, Laboratoire de Physiologic, Hopital Antoine Beclere, 921+1 Claman. France.

Supported by Grant INSERM/CNAMTS 1613 and by Fondation de France. guishable from QS on the basis of different EEG patterns; presence of REM: respiratory, heart rate, and spontaneous skin potential control (2); oxygen consumption, and carbon dioxido production (3).

Little is known about differences between $A S$ and $Q S$ in infants under 31 w GA. Drevfus-Brisac (4) found no cyclic organization of EEG. REM, and body movement or heart and respiratory rate between 24 and 27 w GA. Monod and Garma (5) found only undifferentiated sleep in three infants of 30-31 w GA. On the contrary, in a study based on EEG recordings and visual monitoring of eye and body movements, Karch et al. (6) found well-defined $A S$ and $Q S$ states in ventilated and spontaneously breathing premature infants from $28-33 \mathrm{w}$ GA, although the study reported no other information on sleep structure at this age. Dittrichova and Paul (7) noted that both states could be observed at 32 w GA.

Because evidence of state-dependent differences in respiratory regulation has been found in artificially ventilated premature infants $>28$ w GA $(8,9)$, we considered that sleep organization in very young premature infants needed further study. Consequently, we designed the present study in neurologically normal premature infants. Our aim was principally to answer two questions: 1) Does sleep state differentiation exist in 27-34 w GA premature infants and. in the event of an affirmative answer, what are the appropriate criteria for coding states at this age? 2) Is sleep organization modified by mechanical ventilation used to treat respiratory distress syndrome. which is one of the most common conditions in very premature babies?

\section{MATERIALS AND METHODS}

Subjects. This study was carried out on 24 neurologically normal premature infants, separately investigated in three groups of eight subjects each according to $\mathrm{GA}$ on the day of recording: mechanically ventilated, 27-30 w GA infants; mechanically ventilated 31-34 w GA infants: and spontancously breathing 31-34 w $G A$ infants (Table 1). Recordings were performed when infants were clinically stabilized, in many cases on the day before wean-

Table 1. Age and sleep) duration in different groups studied (mean $\pm S D$, range')*

\begin{tabular}{|c|c|c|c|c|}
\hline Group & $\begin{array}{c}\text { Gestational age } \\
\text { at birth (wh) }\end{array}$ & $\begin{array}{l}\text { Postnatal } \\
\text { agc (d) }\end{array}$ & $\begin{array}{c}\text { Gestational age } \\
\text { when recorded } \\
\text { (wk) }\end{array}$ & $\begin{array}{l}\text { Slece dura- } \\
\text { tion (min) }\end{array}$ \\
\hline V 27-30 & $\begin{array}{c}28.1 \pm 0.9 \\
(26.3-29.1)\end{array}$ & $\begin{array}{c}9.8 \pm 4.3 \\
(3-16)\end{array}$ & $\begin{array}{l}29.5 \pm 1.2 \\
(27-30.7)\end{array}$ & $\begin{array}{c}110 \pm 25.1 \\
(74.7-152.7)\end{array}$ \\
\hline V $31-34$ & $\begin{array}{r}29.1 \pm 1.3 \\
(27-3() .7)\end{array}$ & $\begin{array}{c}21.4 \pm 15.8 \\
(5-43)\end{array}$ & $\begin{array}{l}32.2 \pm 1.2 \\
(31-34.4)\end{array}$ & $\begin{array}{l}112 \pm 28.9 \\
(85-165)\end{array}$ \\
\hline N $31-34$ & $\begin{array}{l}31.8 \pm 1.7 \\
(30-34.1)\end{array}$ & $\begin{array}{c}6.4 \pm 1.9 \\
(4-9)\end{array}$ & $\begin{array}{l}33.0 \pm 1.5 \\
(31-34.8)\end{array}$ & $\begin{array}{l}122 \pm 26.1 \\
(63.3-145)\end{array}$ \\
\hline
\end{tabular}

* V, mechanically ventilated; $N$, nonventilated infants. Note that days are transformed to weeks using a decimal system. 
ing from mechanical ventilation. Each mother gave her consent after receiving a detailed explanation of the method of recording and aim of the study. Data obtained by polygraphy were part of a routine neurologic status and GA evaluation.

GA was determined on the basis of concordance of the following criteria: 1 ) first day of the last menstrual period (only babies born to women with regular menstrual periods were included); 2) clinical and neurologic data; 3 ) weight, body length, and head circumference (10); and 4) EEG pattern (11). Mechanical ventilation was performed because of acute neonatal respiratory distress syndrome related to hyaline membrane disease. Neurologic normality was established on the basis of findings upon neurologic evaluation, EEG, and ultrasound transfontanellar echoencephalography. Recordings were performed in the neonatal department in the morning (from 0900 to $1300 \mathrm{~h}$ ). All infants were lying in incubators with temperature $\left(30-36^{\circ} \mathrm{C}\right)$ adapted to maintain normal body temperature. The study did not influence routine clinical care. All infants were in the supine position.

Polysomnography. Polygraphic recordings (Figure 1) included monitoring of centro-occipital, left and right bipolar EEG channels, REM and limb movements (recorded with piezo-electric crystal transducers), thoracic and abdominal respiratory movements, pulse oxymetry (transcutaneous arterial $\mathrm{O}_{2}$ saturation), and ECG and cardiotachographic tracings. Respiratory air flow was recorded by nasal thermistors in normal infants. In mechanically ventilated infants, air flow given by the ventilator was recorded by a Fleisch 00 pneumotachograph connected to the inspiratory circuit. Polygraphic data were simultaneously recorded on paper and magnetic tape. Infant behavior was continuously monitored by two independent observers.

Sleep state analysis. Sleep was defined by eyes being closed (however, brief eye opening and closing related to REM were accepted in AS) and no continuous general body movements lasting more than $1 \mathrm{~min}$. Tracings were interrupted when spontaneous waking or crying lasted $>10 \mathrm{~min}$.

Characteristics of three polygraphic parameters were independently coded by 20 -s epochs by two independent experienced observers and later related to different sleep states as follows: 1 ) EEG patterns, characteristic for the given GA (11). AS was characterized by continuous theta plus delta or delta activity. Delta activity present in more than $70 \%$ of a given 20 -s period was coded as a continuous tracing. QS was characterized by a discontinuous tracing. 2) REM: present in AS, absent in QS. 3) Body movements: present in AS, absent in QS.

We performed two independent codings of sleep states according to the simultaneous presence of two or three criteria, as

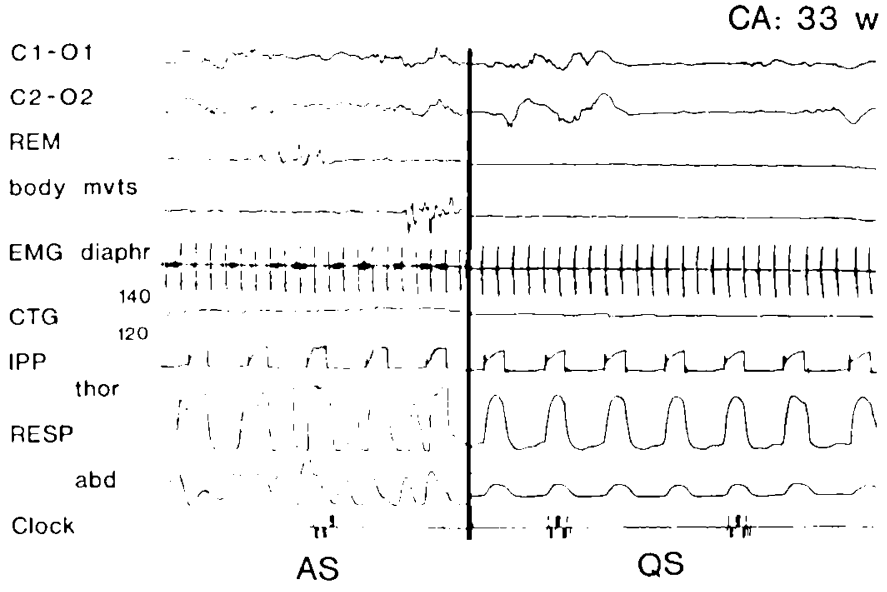

Fig. I. Example of polygraphic recording from a 33 wk conceptional age (C.1) mechanically ventilated infant. $\mathrm{Cl}-\mathrm{O} 1, \mathrm{C2}-\mathrm{O} 2$, bipolar EEG; $m v t s$, movements; $E M / G$, surface diaphragmatic electromyogram; $C T G$, cardiotachography; RESP, respiratory movements recorded at the thoracic $(t h o r)$ and upper abdominal $(a b d)$ level; $I P P$, mechanical intermittent positive pressure ventilation. follows: $1=\mathrm{EEG}$ patterns + REM, and, $2=\mathrm{EEG}$ patterns + REM + body movements.

The beginning of an AS or QS state was defined by the simultaneous presence of the relevant parameters for at least 1 min (12). Interruption of concordance between the selected parameters for $1 \mathrm{~min}$ or more was considered as denoting interruption of the state. Periods that did not fulfill criteria for either AS or QS were coded as IS. Periods for which interobserver agreement concerned less than $90 \%$ of the duration of a given parameter were also classified as IS.

We studied the following sleep parameters: I) duration, percentage, and number of epochs of AS, QS, IS, and waking in the total tracing; 2) duration of the longest uninterrupted AS, QS, and IS period observed in the total tracing; 3 ) duration of the longest complete sleep cycle (including one AS and one QS period) in a given tracing; 4) duration, percentage, and number of epochs of AS, QS, and IS in the longest sleep cycle; and 5) latencies from the beginning of recording to the beginning of the first QS and the longest sleep cycle.

Data were statistically tested by Mann-Whitney nonparametric analysis of variance and Wilcoxon's matched-pairs signed-ranks test.

\section{RESULTS}

Total tracing duration and total sleep duration in a given tracing were not significantly different in the three groups studied. All infants fell asleep during electrode fixing. Thus, we have no polygraphic information on mode of sleep onset. All polygraphic tracings began by AS or IS.

A. Data on Total Tracing Duration. Mean percentage of recording time spent awake was 2.1 to $4.2 \%$ with no statistically significant differences between groups.

a. Scoring by concordance of EEG + REM criteria. The mean number of state epochs recorded was similar in all groups, variable across tracings, and dependent on sleep state. We found one to three AS and QS epochs and one to five IS epochs per tracing. Table 2 shows the longest uninterrupted AS, IS, and QS periods observed. In all infants, we found at least one continuous AS period of more than $13 \mathrm{~min}$ duration. In all but one subject, a 33 w GA mechanically ventilated infant, QS periods of more than 5 min duration were observed. In all groups, longest AS was significantly longer than longest QS $(p<0.02)$ and IS $(p<$ $0.05)$.

Latency of the first period of QS, which is the state in which EEG abnormalities are most striking, ranged from 1 to $84 \mathrm{~min}$ (Table 3).

Sleep duration and percentage of different sleep states in total tracings are given in Table 4 . There were large between-subject differences $(p<0.001$ for all comparisons). AS percentage in total tracing was significantly higher than QS percentage in mechanically ventilated 31-34 w GA $(p<0.01)$ and nonventilated 31-34 w GA infants $(p<0.05)$. No significant betweengroup differences were found, except for a higher percentage of AS in mechanically ventilated $31-34$ w GA infants as compared with nonventilated $31-34$ w GA infants $(p<0.03)$.

$b$. State scoring by concordance of EEG, REM, and body move'ment criteria. Body movements were recorded in all non-

Table 2. Longest uninterrupted periods of $A S, I S$, and $Q S$ in total tracing in min (coding by $E E G+R E M$ criteria)*

\begin{tabular}{ccrr}
\hline Group & \multicolumn{1}{c}{ AS } & \multicolumn{1}{c}{ IS } & \multicolumn{1}{c}{ QS } \\
\hline V 27-30 & $23.6 \pm 7.7$ & $8.9 \pm 2.8$ & $11.0 \pm 4.1$ \\
& $(13.6-38.3)$ & $(5.3-14.0)$ & $(6.3-16.6)$ \\
V 31-34 & $30.9 \pm 16.6$ & $9.5 \pm 6.5$ & $8.3 \pm 4.2$ \\
& $(15.3-67.3)$ & $(1.3-23.0)$ & $(1.6-15.0)$ \\
N 31-34 & $30.0 \pm 10.9$ & $15.3 \pm 7.5$ & $17.6 \pm 8.2$ \\
& $(13.0-44.3)$ & $(4.3-25.3)$ & $(7.6-33.6)$ \\
\hline
\end{tabular}

$* \mathrm{~V}$, mechanically ventilated; $\mathrm{N}$, nonventilated. 
Table 3. Interval in min between beginning of tracing and beginning of lst QS state and longest sleep cycle in given tracing*

\begin{tabular}{ccc}
\hline Group & $1 \mathrm{st}$ QS & Longest sleep cycle \\
\hline V 27-30 & $18.6 \pm 20.6$ & $39.7 \pm 18.6$ \\
& $(1.0-63.6)$ & $(10-59.6)$ \\
V 31-34 & $26.1 \pm 11.2$ & $35.0 \pm 17.2$ \\
& $(1.6-39.0)$ & $(9.3-71.3)$ \\
N 31-34 & $22.7 \pm 16.8$ & $30.0 \pm 27.6$ \\
& $(0-43.6)$ & $(5.0-84.6)$ \\
\hline
\end{tabular}

* $V$, mechanically ventilated; $n$, nonventilated.

Table 4. Sleep duration and percentage of sleep states (coded by $E E G+R E M$ criteria) in total tracing*

\begin{tabular}{cccc}
\hline Group & AS $(\%)$ & 1S $(\%)$ & QS $(\%)$ \\
\hline V 27-30 & $42 \pm 11.2$ & $31.8 \pm 4.5$ & $27.3 \pm 11$ \\
& $(27.3-58.8)$ & $(23.4-38.8)$ & $(14.8-47.5)$ \\
V 31-34 & $57.1 \pm 27.7$ & $27.1 \pm 19.0$ & $15.7 \pm 8.3$ \\
& $(22.6-90.3)$ & $(6.4-65.2)$ & $(3.3-25.1)$ \\
N 31-34 & $45.1 \pm 14.2$ & $29.7 \pm 10.8$ & $25.1 \pm 7.5$ \\
& $(27.1-73.3)$ & $(7.4-39.5)$ & $(11.7-33.4)$ \\
\hline
\end{tabular}

*V, mechanically ventilated; $N$, nonventilated.

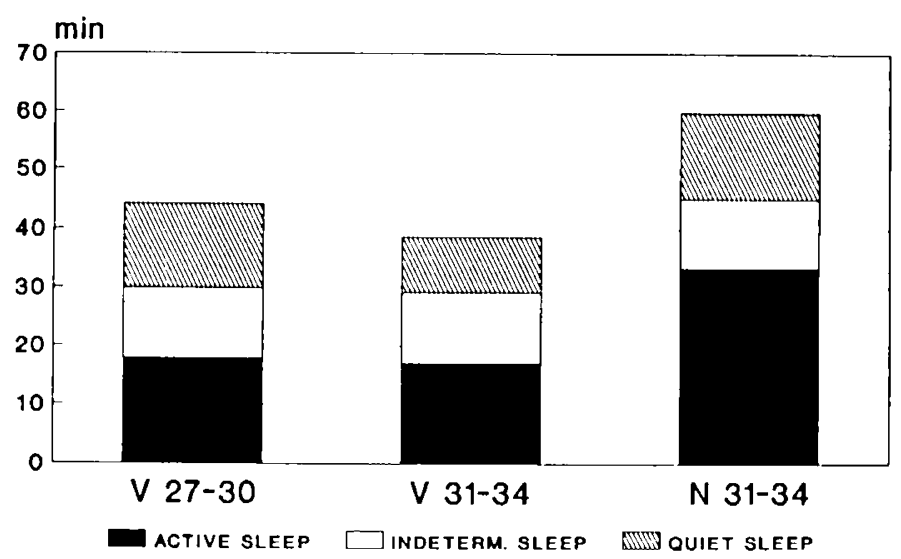

Fig. 2. State duration in $\min$ in the longest sleep cycle observed in individual babies. $V$, mechanically ventilated; $N$, nonventilated infants. The mumbers under the hars indicate gestational age.

ventilated infants and in six of eight infants in each of the mechanically ventilated groups. In every case, we found movement-free AS periods of variable duration, whereas movements occurred during many QS periods. Consequently, AS and QS were significantly shortened $(p<0.02)$. IS was augmented by $45.6 \%$ in $27-30 \mathrm{w}$ GA, $84.5 \%$ in mechanically ventilated $31-34$ w GA infants, and $40 \%$ in nonventilated $31-34$ w GA infants. In spite of total $\mathrm{AS}$ and $\mathrm{QS}$ reduction, in all groups percentage of AS remained significantly higher than percentage of QS $(p<$ $0.05)$. No significant between-group differences were found.

B. Organization of Longest Slecp Cicle. Latency from the beginning of recording to the beginning of the longest sleep cycle was variable, from 5 to $84 \mathrm{~min}$ (Table 3 ).

a. Data obtained by scoring according to EEG and REM criteria. One to four sleep cycles per tracing were recorded. Cycle duration, including $\mathrm{AS}, \mathrm{QS}$, and in most cases IS, ranged from 18.7 to $63 \mathrm{~min}$ in mechanically ventilated infants and from 40 to $85 \mathrm{~min}$ in nonventilated infants. Mean cycle and sleep state durations are given in Figure 2. Mean duration of the longest sleep cycle was $44 \mathrm{~min}$ in mechanically ventilated $27-30 \mathrm{w}$ GA infants, $39 \mathrm{~min}$ in mechanically ventilated $31-34$ w GA infants, and $60 \mathrm{~min}$ in nonventilated infants $(p<0.03$ between mechanically ventilated and nonventilated 31-34 w GA infants). The longer sleep cycle duration in nonventilated 31-34 w GA infants was principally due to longer AS periods in this group compared with the two groups of mechanically ventilated infants $(p<$ 0.01 ). However, in spite of cycle duration differences, structure of sleep cycles was similar, with closely similar percentages (no significant differences) in all three groups.

b. Data obtained by scoring according to EEG, REM, and body move'ment criteria. The significant decreases in AS and QS and the increase in IS were of similar magnitude as in the total tracing analysis. Cycle duration was slightly modified because of IS augmentation. However, in all but one $28 \mathrm{w} \mathrm{GA}$ infant (in whom AS nearly disappeared), cyclic organization of sleep persisted.

\section{DISCUSSION}

The present study demonstrates that, as early as $27 \mathrm{w} \mathrm{GA}$. stable concordance between EEG patterns and presence or absence of REM allows differentiation of AS and QS states.

To the best of our knowledge, similar quantitative polygraphic investigations of sleep organization before $31 \mathrm{w} \mathrm{GA}$ have never before been performed. The study by Monod and Garma (5) focused on auditory responsiveness in premature infants. These authors found IS only before $31 \mathrm{w}$ GA, but this finding was possibly due to sleep disturbance by repetitive auditory stimulation. In another study, Karch et al. (6) mentioned that they detected AS and QS in infants of 28 to $33 \mathrm{w} \mathrm{GA}$ but gave no further information on this topic. In these two studies, as well as in the work by Dreyfus-Brisac (4), EEG was the only parameter recorded, whereas REM and body movement parameters were visually monitored. It is known that use of piezo-electrical quartz transducers provides more accurate and quantitatively different detection of REM, as compared with visual or oculographic monitoring (13).

Sleep organization, evaluated by the concordance of recorded EEG and REM parameters, showed virtually no changes from 27 to 34 w GA. At $27-30$ w GA as well as at $31-34$ w GA, the amount of AS was significantly higher than the amount of QS, and IS accounted for a substantial proportion of sleep. In this work, we studied state distribution in the best organized and longest sleep cycle observed in a given recording. Some of the data thus obtained in normal 31-34 w GA infants were slightly different from our data obtained in a previous study involving analysis of the first sleep cycle (12): the sleep cycle analyzed was longer, with a mean duration of $60 \mathrm{~min}$ i'ersus $46 \mathrm{~min}$ previously, and the percentage of IS was lower, i.e. $18.5 \%$ versus $31.4 \%$ previously. These differences illustrate the difficulty of comparing data from different studies that are not strictly identical with respect to recording method, state coding or, as in the present case, choice of the periods studied. The aim of our present study was to analyze the best state differentiation that can be achieved by premature infants; this goal explains why we modified our methods of cycle analysis. Our data differ in many aspects from findings reported in 1960s and 1970s. In a review of the literature (mainly of reports published before 1980), Lombroso (14) reported that before $29 \mathrm{w} \mathrm{GA}$ "the EEG patterns are invariantly discontinuous" and "organization of states cannot be recognized." In all 27-30 w GA infants, we observed periods of uninterrupted AS of more than 13 min duration, i.e. periods accompanied by continuous or near-continuous EEG tracing. In all these infants, we detected stable QS periods of more than 6 min duration. Because the authors cited by Lombroso are wellknown authorities on sleep in infants, and because the occurrence of changes in CNS structure over the last $20 \mathrm{y}$ is improbable, we conclude that very young premature infants sleep better now than before and hypothesize that this improvement is due to improved care and control of homeostasis in intensive care units. This hypothesis is supported by our personal experience: premature infant recordings used in the present study, which were obtained between 1986 and 1991, demonstrated better sleep organization than premature infant recordings obtained by some of us between 1968 and 1971 (unpublished data). 
Since the description of the rest-activity cycle and its agerelated evolution in animals $(15,16)$. rest-activity cycle and slecp state organization have sometimes been confused. Rest-activity cycle organization studies are based only on body movement evaluation. The present study shows that body movements are not perfectly correlated with EEG and REM parameters. Although percentage of time spent with movements is higher in AS than in QS (17), presence or absence of body movements is unreliable for defining sleep states in very premature infants (the present study), as well as in newborns up to normal term (12): in both premature and full-term infants, body movements are present during more than $50 \%$ of QS and continue to be present during many QS periods during the first months of life (18).

Advances in real-time ultrasonography since 1980 (19) have allowed the demonstration of the presence of behavioral states in the human fetus resembling those described in neonates. The time of first appearance of behavioral states in utero is controversial, as it is for premature infants. Okai ct al. (20), simultaneously using three ultrasonic real-time scanners, observed stable $>3$ min duration REM and non-REM periods between 28 and 31 w GA. The correlation between the occurrence of REM and breathing movements was high after 27 w GA. Nijhuis et al. (21) reported that behavioral states in human fetuses developed between 36 and 38 w GA. Criteria for state definition were quite different in these two studies. Nijhuis et al. emphasized "that the existence of behavioral states can only be accepted if three requirements are satisfied: 1) coincidence of parameters, 2) duration of stable association. and 3) simultaneity of changes at state transition." The first two conditions are without a doubt fundamental for state recognition in both fetuses and newborns. but simultaneity of parameter changes is difficult to satisfy. at least in newborns. As described in full-term newborns (22), transition from one sleep state to another results from progressive, usually nonsimultancous modifications in parameters characteristic for a given state.

Choice of behavioral and polygraphic criteria for state definition is inevitably arbitrary. Our present study was principally based on evaluation of concordance between age-specific EEG patterns and REM parameters. These two parameters are routinely used for categorical classification of sleep states in adults (23) and older infants (2). We believe that use of a similar methodology facilitates evaluation of maturative. age-related modifications in sleep states. Many data from the literature suggest that sleep state maturation consists of progressive elaboration of concordance between specific parameters characteristic of sleep states in older infants and adults. Concordance between EEG patterns and REM is the earliest means of contrasting AS and QS. Differentiation of sleep states according to these two variables is accompanied by sleep-related modulation of respiratory, motor. and cardiac function control. In mechanically ventilated infants, beyond $28 \mathrm{w} \mathrm{GA}$, ventilator dependency is greater during QS than during AS (8.9). Spontancous skin potential responses become more marked in AS compared with QS at 31 w GA (24). At 31-34 w GA (lower age limit of the studies), significant between-state differences have been observed for numerous parameters. Age-related modifications in betweenstate differentiation have been previously reviewed in one of our papers (2). The recent study by Easton et al. (25) confirmed that preterm infants, beyond $35 \mathrm{w}$ GA, show stability in their sleep states, REM, and respiratory characteristics.

The influence of the neonatal intensive care environment on the infant brain and behavior has been addressed by many investigators (26-28). In a recent study, Glotzbach ot al. (29) showed that biologic rhythmicity in preterm infants before discharge to home was dominated by ultradian components that correlated highly with feeding. Our data demonstrated that. in neurologically normal, clinically stabilized premature infants, mechanical ventilation per se did not prevent sleep state organization. Normal 31-34 w GA premature infants showed the ability to achieve longer sleep cycles, but sleep state organization in a cycle was observed in both mechanically ventilated and spontancously breathing infants, who had similar percentages of AS, QS, and IS.

Finally, our study emphasizes that long-duration polygraphic recordings are essential for the evaluation of EEG and sleep organization in premature infants. The presence of two states is considered a good prognosis in newborns when neurologic damage is suspected (30-32). Some EEG abnormalities appear mainly in QS. In some of our subjects, the first QS appeared after 63 min and the longest sleep cycle began after 84 min of recording.

In conclusion, the present study demonstrates that sleep state differentiation appears early in human ontogenesis. On the basis of EEG and REM concordance, well-defined stable periods of AS and QS are identifiable starting at 27 w GA in non-braindamaged infants. Mechanical ventilation. performed in specialized neonatal intensive care units, does not significantly modify sleep organization. Knowledge of state differentiation in very premature infants is important for the understanding of state modulation of vital functions at this age.

Acknowledgment. The authors thank Dr. A. Wolfe for critical review and correction of the English-language manuscript.

\section{REILRENCES}

1. Prechtl HFR 1974 The behavioural states in the newhorn infant. [review] Brain Res 76:185-212

2. Curzi-Dascalova L 1992 Physiological correlates of sleep development in premature and full-term newhorns. Neurophysiol Clin 22:151-166,

3. Dane HJ, Sauer PJJ, Visser HKA 1985 Oxygen consumption and $\mathrm{CO}_{2}$ production in low-birth-weight infants in two sleep states. Biol Neonate 47:205210

4. Dreyfus-Brisac $\mathrm{C} 1968$ Sleep ontogenesis in early human prematurity from 24 to 27 weeks of conceptional age. Dev Psychobiol 1:162-169

5. Monod N. Garma L 1971 Auditory responsiseness in the human premature. Biol Veonate 17:292-316

6. Karch D. Rohmer K. Lemburg P 1984 Prognostic significance of polygraphic recordings in newborn infants on ventilation. Dev Med Child Neurol 26:358368

7. Dittrichova J. Paul K 1983 Development of hehavioural states in very premature infants. Arch Nerv Sup (Praha) 25:187-188

8. Curzi-Dascalova L. Relier JP. Peirano P. Castex M, Vasseur O 1986 Degree of dependence on the ventilator according to sleep states in artificially ventilated premature infants. Am J Perinatol 3:169-173

9. Habbib $\mathrm{M} 1990$ Le zolpidem (Stilnox) che le nouveau-ne ventile. Memoire de recherche, Universite de Nancy I, Nancy, France. 34 pp

10. Goujard J, Kaminshi M. Rumeau-Rouquette C 1973 Moyenne ponderale et age gestationnel en relation avec quelque caractiristiques maternelles. Arch Franc Ped 30:341-362

11. Drevfus-Brisac C 1979 . Neonatal electroencephalography. In: Cosmi EV. Scarpelli EM (eds) Reviews in Perinatal Medicine. Vol 3. Raven Press. New York. pp 397-472

12. Curzi-Dascalova L. Peirano P. Morel-Kahn F 1988 Development of sleep states in normal premature and full-term newhorns. Dev Psychobiol 21:431-444

13. Pajot N. Vicente (i. Dreyfus-Brisac C 1976 Techniques denregistrement des mouvements oculaires chez le nouveau-né: comparaison des methodes. J Electrophysiol Technol 2:29-38

14. Lombroso CT 1985 Neonatal polygraphy in full-term and premature infants: a review of normal and abnormal findings. J Clin Neurophysiol 2:105-155

15. Corner MA. Kwee P 1976 Cyclic EEG and motility patterns during sleep in restrained infant rats. Electroencephalogr Clin Neurophysiol 41:64-72

16. Belich AI, Natsvilishvili VV 1989 The development of the rest-activity cycle in human fetus. Vestn Akad Med Nauk SSSR 3:35-42

17. Peirano P. Curri-Dascalova L. Korn G 1986 Influence of sleep state and age on body motility in normal premature and full-term neonates. Neuropediatrics $17: 186-190$

18. Vecchierini-Blineau MF. Nogues B. Louvet S 1989 Evolution des mouvements corporels glohaux au cours du sommeil chez des nourrissons témoins, ages de 1 a 4 mois. Neurophysiol Clin 19:231-239

19. Prechtl HFR 1985 Ultrasound studies of human fetal behaviour. Early Hum Dev 12:91-98

20. Okai T, Kozuma S, Shinozuka N. Kuwabara Y. Mizuno M1992 A study on the development of sleep-wakefulness cycle in the human fetus. Early Hum Dev 29:391-396

21. Nijhuis J. Martin C. Prechtl H. Bots R 1983 The implication of fetal behavioural states for perinatal monitoring. Eur J Obstet Gynecol Reprod Biol $15: 4.33-4.36$

22. Curri-Dascalova L. Monod N. Guidasci S. Korn G 1981 Transition veillesommeil chez le nouveau-ne et le nourrisson avant l'age de 3 mois. Rev IEEG Neurophysiol 11:1-10

23. Rechtschaflen A. Kales A (eds) 1968 A Manual of Standardized Terminology. 
Techniques and Scoring System for Sleep Stages in Human Subjects. Nittional Institute of Health. Bethesda, MD

24. Curzi-Dascaloava L., Pajot N. Drevfus-Brisac C 1973 Spontaneous skin potential responses in sleeping infants between 24 and 41 weeks of conceptional age. Psychophysiology 10:478-487

25. Easton CJ, Afllech G. DeSilva H. Fine MD. Stuynski KA. Thoman EB 1992 Stability of sleep states and respiration in preterm infants. Sleep Res 21:83

26. Leahy F. Durand M. Cates D. Chernich V 1982 Cranial blosd volume changes during mechanical ventilation and spontaneous breathing in newborn infants. J Pediatr 101:984-987

27. McMillen IC. Kok JSM, Adamson TM. Deagkon JM. Nowak R 1991 Development of circadian sleep-wake rhythms in preterm and full-term intants. Pediatr Res 29:381-38-
28. Scher MS. Richardson GA. Salerno DG. Day NL. Guthri RD 1992 Skep architecture and continuity measures of neonates with chronic lung discase. Sleep 15:195-2(0)

29. Gilowhach SF. Edgar DM. Boeddiker MA. Ariagno RL 1992 Biological rhythmicity in preterm infants: exogenous factors. Sleep Res 21:85

30. Monod N. Guidasci S 1976 Sleep and brain malformation in the neonatal period. Neuropadiatric $7: 229-249$

31. Parmelee AII. Ciarbanati JA 1987 Clinical neurohehavioral aspects of state organization in newborn infants. In: Yabuuchi ll. Watanate $K$. Okada $S$ (cds) Nconatal Brain and Behavior. University of Nagoyia Press. Nagoya. Japan, pp $131-144$

32. Hellstrom Westats L. Rosen I. Sweningsen NW 1991 Cerchral function monitoring during the first week of life in extremely smalt low birth weight (ELBW ) infants. Neuropediatrics 22:27-32

\section{Announcement}

\section{Nominations for the 1994 E. Mead Johnson Award for Research in Pediatrics}

Nominations are invited for the 1994 E. Mead Johnson Award for Research in Pediatrics. Each of two recipients will receive an honorarium of $\$ 10,000$ plus travel expenses to attend the 1994 meeting of the Society for Pediatric Research in Seattle. WA, where recipients will present their research at a special seminar.

Eligibility for the 1994 award:

1) Nominees must have received their doctoral degree in 1974 or later

2) Limited to investigators in the Americas

3) Research is related to pediatrics and recently published, perhaps coming to fruition or attaining recognition during the past few years

Candidates are nominated by their Department Chairs or past E. Mead Johnson Award recipients. The deadline for submission is December 3. 1993. Nomination forms may be obtained from: Debbie L. Anagnostelis. The Society for Pediatric Research, P.O. Box 675. Elk Grove Village, IL 60009-0675. 